\title{
Article \\ Interior Sound Quality Prediction of Pure Electric Vehicles Based on Transfer Path Synthesis
}

\author{
Kun Qian ${ }^{1, *(\mathbb{C})}$, Zhichao Hou ${ }^{1, *}$, Jie Liang ${ }^{2}$, Ruixue Liu ${ }^{1}$ and Dengke Sun ${ }^{3}$ \\ 1 State Key Laboratory of Automotive Safety and Energy, Tsinghua University, Beijing 100084, China; \\ liuruixue0218@163.com \\ 2 State Key Laboratory of Automotive Simulation and Control, Jilin University, Changchun 130022, China; \\ liangjie1965@163.com \\ 3 School of Mechanical Electronic and Information Engineering, China University of Mining and \\ Technology-Beijing, Beijing 100083, China; sundengke_nvh@163.com \\ * Correspondence: qiankun_nvh@163.com (K.Q.); houzc@tsinghua.edu.cn (Z.H.); \\ Tel.: +86-010-6279-7088 (K.Q.)
}

Citation: Qian, K.; Hou, Z.; Liang, J.; Liu, R.; Sun, D. Interior Sound Quality Prediction of Pure Electric Vehicles Based on Transfer Path Synthesis. Appl. Sci. 2021, 11, 4385. https://doi.org/10.3390/app11104385

\section{Academic Editors:}

Giovanni Bernardini, Raffaele Tuccillo and Mattia Barbarino

Received: 15 April 2021

Accepted: 11 May 2021

Published: 12 May 2021

Publisher's Note: MDPI stays neutral with regard to jurisdictional claims in published maps and institutional affiliations.

Copyright: (c) 2021 by the authors. Licensee MDPI, Basel, Switzerland. This article is an open access article distributed under the terms and conditions of the Creative Commons Attribution (CC BY) license (https:// creativecommons.org/licenses/by/ $4.0 /)$.

\begin{abstract}
The interior sound quality (SQ) of pure electric vehicles (PEVs) has become an important consideration for users purchasing vehicles. At present, it is insufficient to take the sound pressure level as the interior acoustics design index of PEVs. Transfer path analysis (TPA) and transfer path synthesis (TPS) that take the SQ of interior noise as the improvement target remains in the preliminary exploration stage. In this paper, objective psychoacoustic parameters of SQ were taken as evaluation indexes of interior PEV noise. A virtual interior SQ synthesis model was designed on the basis of TPA and TPS, which combines experimentation and simulation. The SQ synthesis model demonstrates each noise component contribution in a PEV by new SQ separation technology. First, the interior noise transfer path and noise source of the PEV were determined in a synthesis analysis method of the interior PEV noise. Second, on the basis of the composition mechanism of interior noise and the basic principle of TPA, the excitation signal and transfer function of each interior noise path in the PEV were tested. On the basis of TPS, the interior SQ synthesis model of PEV was then established. Finally, the accuracy of the prediction model was verified in simulation and experimental comparison studies on the psychoacoustic objective parameters of SQ. The SQ objective parameter value of each transfer path was quantified by using contribution analysis. The results are expected to improve the comfort of the interior acoustic environment and enhance the competitiveness of vehicle products. They also provide an effective reference and new ideas for the development of interior SQ in PEVs.
\end{abstract}

Keywords: pure electric vehicles; noise; sound quality; transfer path synthesis

\section{Introduction}

The growing energy crisis has severely challenged the future development of conventional internal combustion engine vehicles (ICEVs). Environmentally friendly, low-carbon, and low-emission pure electric vehicles (PEVs) are the certain future trend in the development of the automotive industry. The low noise is a remarkable feature of PEVs $[1,2]$. However, as the motor, electronic control components, and inverter units produce a large amount of annoying high-frequency noise, the noise waveform and spectral structure inside the vehicle are very different from those inside ICEVs, and the subjective evaluations of drivers and passengers significantly differ between the two types of vehicles [3,4]. Although PEVs are quieter than ICEVs, the subjective perceptions of the driver are unsatisfactory, and many interior sound quality (SQ) problems negatively affect the acoustics of PEV and reduce the comfort of the vehicle ride [5-8].

Transfer path analysis (TPA) and transfer path synthesis (TPS) techniques have been widely used in the automotive noise, vibration, and harshness (NVH) industry [9-14]. TPA technology has been a mainstay of ICEVs and has been more recently considered for EVs. 
In-vehicle noise measurements, TPA and TPS accurately determine the composition of specific-frequency noises and their associated transfer paths. Besides assisting SQ design, TPA and TPS provide everyday simplified measurements for commercial applications. The hybrid TPA method developed in $[9,10]$ predicts the interior noise caused by the structure-borne path of a powertrain. This technique is useful for design modification of the powertrain and tuning of the target noise in the early stages of vehicle development. In another TPA study, Reising et al. [11] calculated the contribution of structure-borne noise from the rear final drive to the sound pressure on the driver's ear. Vaitkus et al. [12] proposed an operational TPA (OTPA) for structure-borne noise analysis. The low-frequency vibrations of steering wheels have been reduced by a systematic analysis based on classical TPA [13]. TPA can accurately and effectively determine the composition of the structural vibration transfer path and its impact on the interior noise [14].

The TPA and TPS methods have been increasingly applied to acoustic analyses of EVs [15-21]. For example, TPA has analyzed the contribution of panel noise to an EV [15]. Cao et al. [16] investigated the noise contribution to an EV through experimental measurements and a synthetic method based on TPA principles. Diez-Ibarbia et al. [17] evaluated the influence of harmonic-order noise introduced by different components of the EV. Albers et al. [18] measured and analyzed the transfer path of acoustic phenomena in the driver cabin of a battery electric vehicle using TPA, and Qian et al. [19] accurately predicted the interior electromagnetic noise of an EV by combining TPA with motor electromagnetic vibration simulations. Meanwhile, the OPTA method has effectively improved the cabin noise in an electric minivan by separating the noise contributions from the tires, powertrain, and wind [20]. OTPA infers the effects of the sound sources on the driver's ear from operational measurements. Shiozaki et al. [21] investigated the noise component contribution in EV by new separation technology. Road noise and wind noise influence increase and become a significance factor for EV.

The SQ of ICEVs has a clear and simple research objective. The SQ of an ICEV is predicted and controlled by the technical development of the main noise source (in this case, the ICE power system). As the SQ characteristics of EVs significantly differ from those of ICEVs, the NVH studies will largely differ between PEVs and ICEVs. Therefore, a new sound evaluation method is needed for PEVs. Whether the TPA research method of conventional ICEVs can be quickly applied to the acoustic design of PEVs is not certain. Recently, TPA and TPS usually take the sound pressure level of the interior noise as the evaluation index; TPA and TPS that take the SQ of interior noise as the improvement target remains in the preliminary exploration stage.

This paper predicts the interior SQ of a PEV using TPA and TPS methods and demonstrates each noise component contribution in a PEV by a new SQ separation technology. The remainder of the paper is organized as follows. Section 2 describes the basic principles of interior SQ synthesis model on the basis of TPA and TPS. Section 3 presents the noise transfer functions and noise source excitation along different transfer paths of the PEV. Section 4 compares the predicted and measured results of the SQ inside the PEV, and Section 5 discusses the main noise source and transfer paths by contribution analysis. The research concludes with Section 6.

\section{Materials and Methods}

\subsection{PEV Transfer Path Analysis}

Many factors contribute to the noise in a PEV. As each noise source has its own transfer path and transmission mode, the transfer path of the noise in a PEV is particularly complicated. However, the noise transmission is divisible into only two categories: structure-borne noise and airborne noise. Structure-borne noise is caused by vibrations of a component in the vehicle, which are transmitted to the car body through the connected parts. The resulting vibrations of the vehicle body panel radiate into the cab. Airborne noise arises from the vibrations of each noise source or from internal noise excitation, which radiates noise into the air. The airborne noise is transmitted to the surroundings and then 
reaches the vehicle through other paths such as body panels, holes, gaps, or windows. If the PEV is operating under linear time-invariant conditions, the sound pressure around the human ear in the vehicle can be obtained by superposing the energy of each noise source transmitted to the vehicle. Before reaching the ear, the energies of the excitation sources are attenuated by the structures and air transmissions along the different transmission paths. The sound pressure in the PEV is; thus, calculated as

$$
P_{\text {interior }}=\sum P_{i, \text { air }}+\sum P_{j, \text { structure }}=\sum\left(H_{i, \text { air }} \times P_{i, \text { source }}\right)+\sum\left(H_{j, \text { structure }} \times F_{j, \text { source }}\right),
$$

where $P_{\text {interior }}$ denotes the total noise pressure in the vehicle; $i$ and $j$ are the indices of the airborne and structure-borne noise sources, respectively; $P_{i, a i r}$ and $P_{j, \text { structure }}$ are the pressures of the $i$ th airborne noise sources and the $j$ th structure-borne noise sources, respectively; $H_{i, a i r}$ and $H_{j, \text { structure }}$ are their corresponding transfer functions; $P_{i, \text { source }}$ is the $i$ th airborne noise source excitation; and $F_{j, \text { source }}$ is the $j$ th structure-borne noise source excitation.

The noise composition in a PEV is quite different from that in an ICEV. The noise in a PEV is mainly contributed by electromagnetic noise of the driving motor, the tire noise, oil pump noise, and fan noise of the battery-cooling ventilation system. The structureborne noise is formed from vehicle body vibrations caused by road surface excitations and vibrations of the powertrain through the mount, suspension, and chassis. The total interior noise in a PEV includes airborne and structure-borne noise as described above. Figure 1 schematizes the noise transfer paths through a PEV.

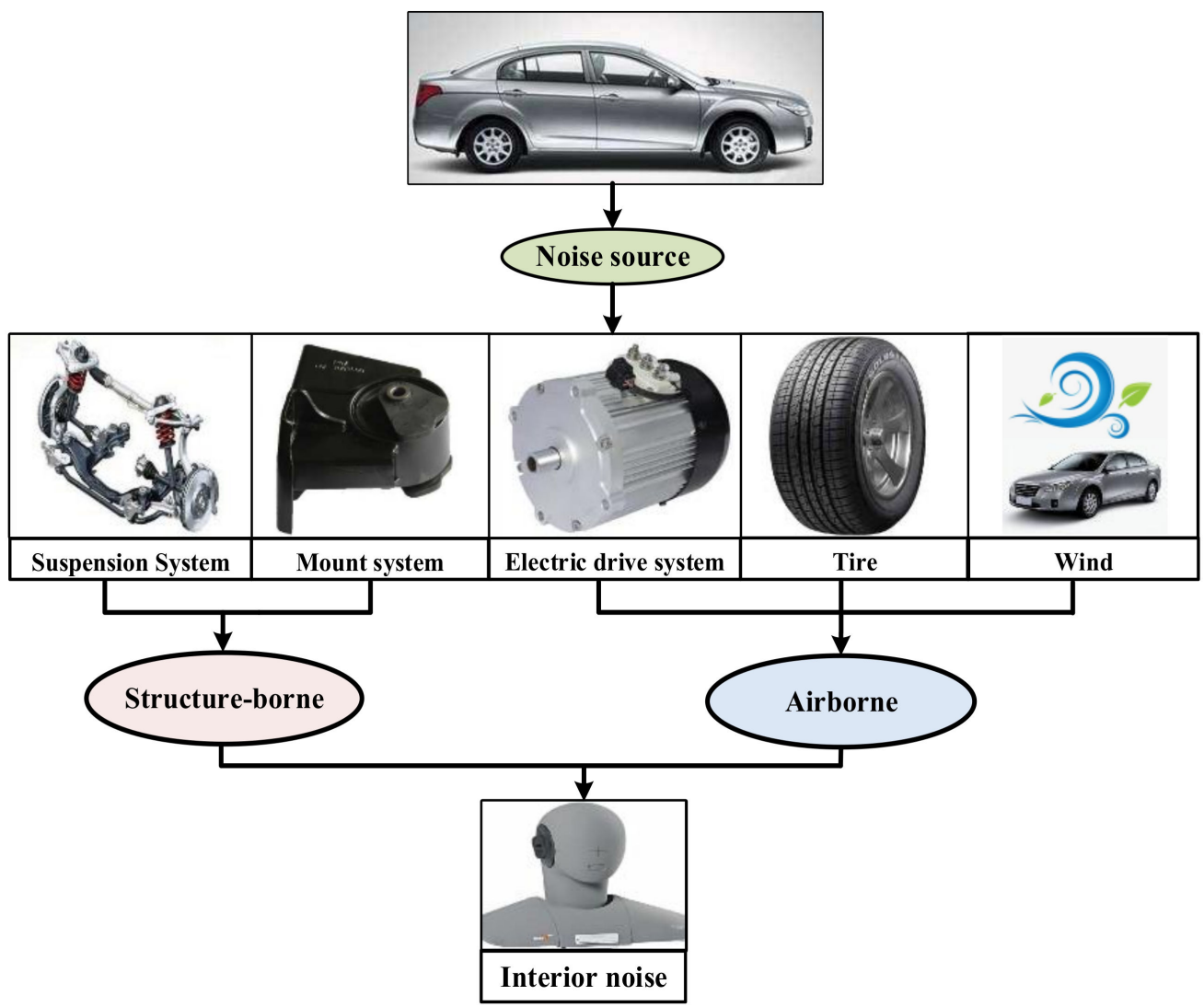

Figure 1. Schematic of the pure electric vehicle (PEV) noise transfer paths.

\subsection{PEV Transfer Path Synthesis}

In this paper, virtual interior sound was synthesized in the PEV and simulated by the TPS method. Although a PEV has no engine, it contains additional motors, battery pack systems, power coupling devices, and other components that change and scatter the layout of the vehicle and increase the number of noise sources. Accordingly, the sound- 
synthetic model in the vehicle is highly complicated. Past experience has shown that, if all noise sources and paths were included in the model, the model became excessively large and requires too much data and workload, ultimately leading to failure of the mission. Therefore, in the modeling process, the model should be simplified to suit the actual situation. In the present model, we studied the contributions of the electric drive system, suspension, mount, and tire to the interior noise, neglecting the influence of wind noise. The whole experiment process was carried out in a semi-anechoic chamber. Therefore, the airborne noise came from the electric drive system and tires, and the structure-borne noises comes from the powertrain mount and suspension systems.

The noise transfer function and source excitation are two basic elements of the interior sound synthesis. Their measurement processes are described below.

(1) Transfer function measurements: The airborne noise transfer function is the frequency response function (FRF) from the noise source to the noise at the target point. The airborne noise transfer function is defined as

$$
H_{i, \text { air }}=P_{\text {target }} / P_{i, \text { source }}
$$

where $H_{i, a i r}$ is the transfer function from the $i$ th noise source to the target point in the vehicle, $P_{\text {target }}$ is the sound pressure of the noise at the target point in the vehicle, and $P_{i, \text { source }}$ is the $i$ th noise source excitation.

The structure-borne noise transfer function measures the FRF in each degree of freedom at the coupling point of the structure to the response position. Note that the active and affected sides should be decoupled at each coupling point during the measurement. The structure-borne noise transfer defines the transfer function from the structure-borne excitation source to the target point inside the vehicle and is expressed as follows:

$$
H_{j, \text { structure }}=P_{\text {target }} / F_{j, \text { source }},
$$

where $H_{j, \text { Structure }}$ is the transfer function from the $j$ th structure-borne noise source to the target point in the vehicle, $P_{\text {target }}$ is the sound pressure level at the target point in the vehicle, and $F_{j, \text { source }}$ is the exciting force of the $j$ th structural noise source.

(2) Noise source excitation measurements: The excitations of airborne noise sources are mainly measured as sound pressure levels or volume acceleration of the noise source, whereas the excitations of structure-borne noise sources are mainly measured as the working force input with different degrees of freedom at the coupling point of the structure. Noise source excitation measurements produce a large number of the experimental data, which directly affect the reliability of the final synthesis model and are requisite for constructing the sound synthesis model.

The sound synthesis model of the PEV used the airborne noise source excitation (motor and tire) and structure-borne noise source excitation (suspension and mount) signals under actual working conditions. The interior airborne and structure-borne noises were simulated in combination with the airborne and structure-borne transfer functions, respectively, and superimposed to give the total interior noise. Figure 2 shows the interior sound synthesis model in the PEV.

The noise sources transmit noise to the vehicle through the air and structure, but they can be transmitted in many transfer paths. The characteristics of each transfer path are not the same, so it is necessary to carry out effective analysis on each transfer path. In order to ensure the reliability of the model and improve the prediction accuracy, appropriate experimental methods should be adopted to obtain the excitation and the transfer function of noise sources. 


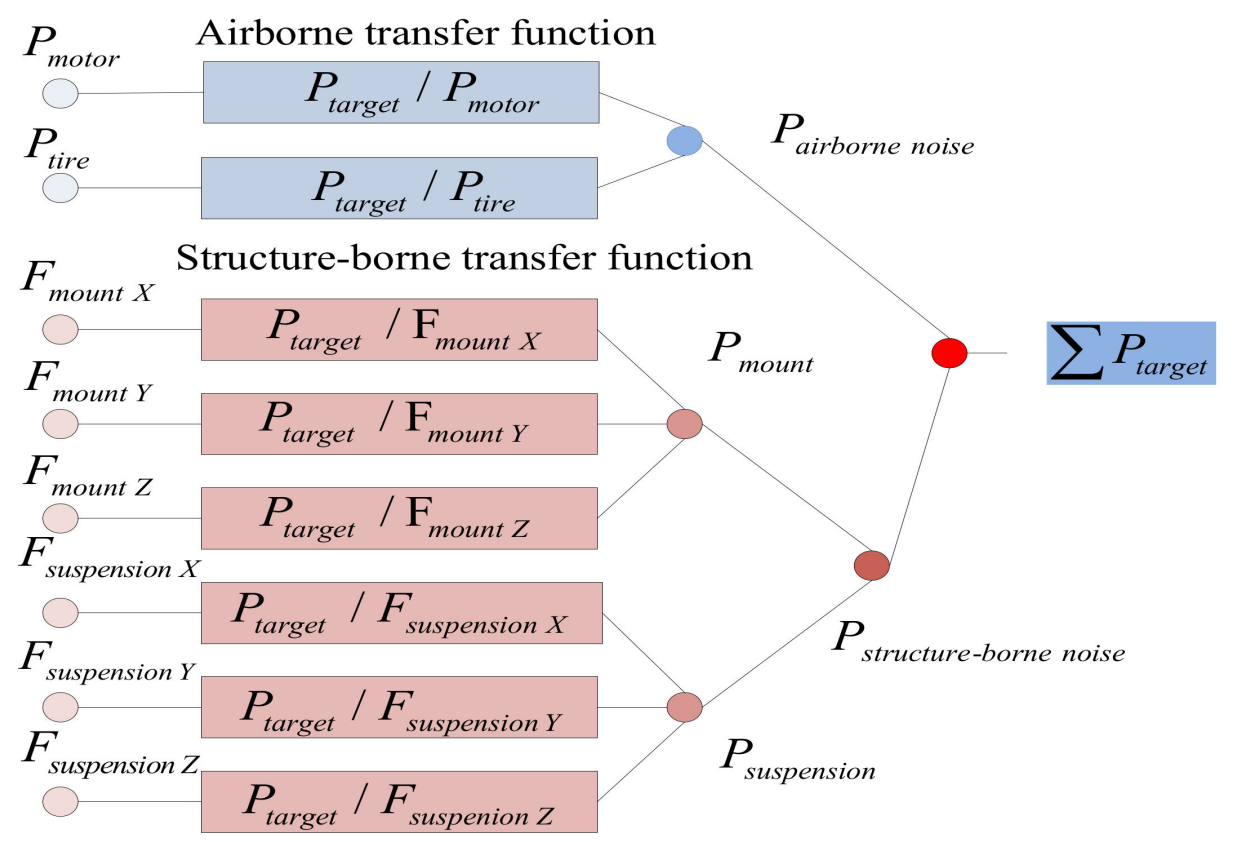

Figure 2. Schematic of the interior sound synthesis model of the PEV.

The electric drive system of the tested PEV was supported by three mounts. The structural transmission noise was transmitted to the vehicle through three body connection points of the front mount, the right mount and the rear mount. Each mount noise excitation was divided into $\mathrm{X}, \mathrm{Y}$, and $\mathrm{Z}$ directions, with a total of 9 structure-borne transfer paths. In this paper, the airborne source quantification (ASQ) technique was used to test the airborne noise of the electric drive system, which was divided into 61 noise sources, so there were 61 transfer paths. There were 18 connection points between the suspension system and the body, and the excitation at each connection point was divided into X, Y and $\mathrm{Z}$ directions, so the suspension system had a total of 54 transfer paths. The tire system was the source of airborne noise. Each of the four tires had one transfer path, each mount noise excitation was divided into $\mathrm{X}, \mathrm{Y}$, and $\mathrm{Z}$ directions, with a total of 9 structure-borne transfer paths. So there were four transfer paths in total. The whole prediction model contained 63 structure-borne noise transfer paths and 65 airborne noise transfer paths, a total of 128 transfer paths, or 128 refined noise sources. The next section estimates the transfer path function of these 128 noise sources and obtains the excitation data.

\subsection{Psychoacoustic Parameters of SQ}

Sound pressure is the most basic physical quantity to quantitatively describe sound waves, where parameters, such as sound pressure, sound intensity, and sound power, among others, are typically considered when describing the physical characteristics of noise. However, these parameters cannot reflect the subjective feelings of a person; hence, objective psychoacoustic parameters have been developed on the basis of considering the auditory characteristics of the human ear as well as fully reflecting subjective feelings [1]. Psychoacoustic parameters have been identified as objective physical quantities that describe the degree of difference in subjective feelings caused by different sound signals and which can eliminate the unstable factors of subjective evaluations. At present, the more commonly used parameters are loudness, sharpness, and roughness [22]. After we obtained the synthesized sound in the vehicle, we could objectively analyze the SQ of the synthesized sound in each transmission path according to the process in Figure 3. 


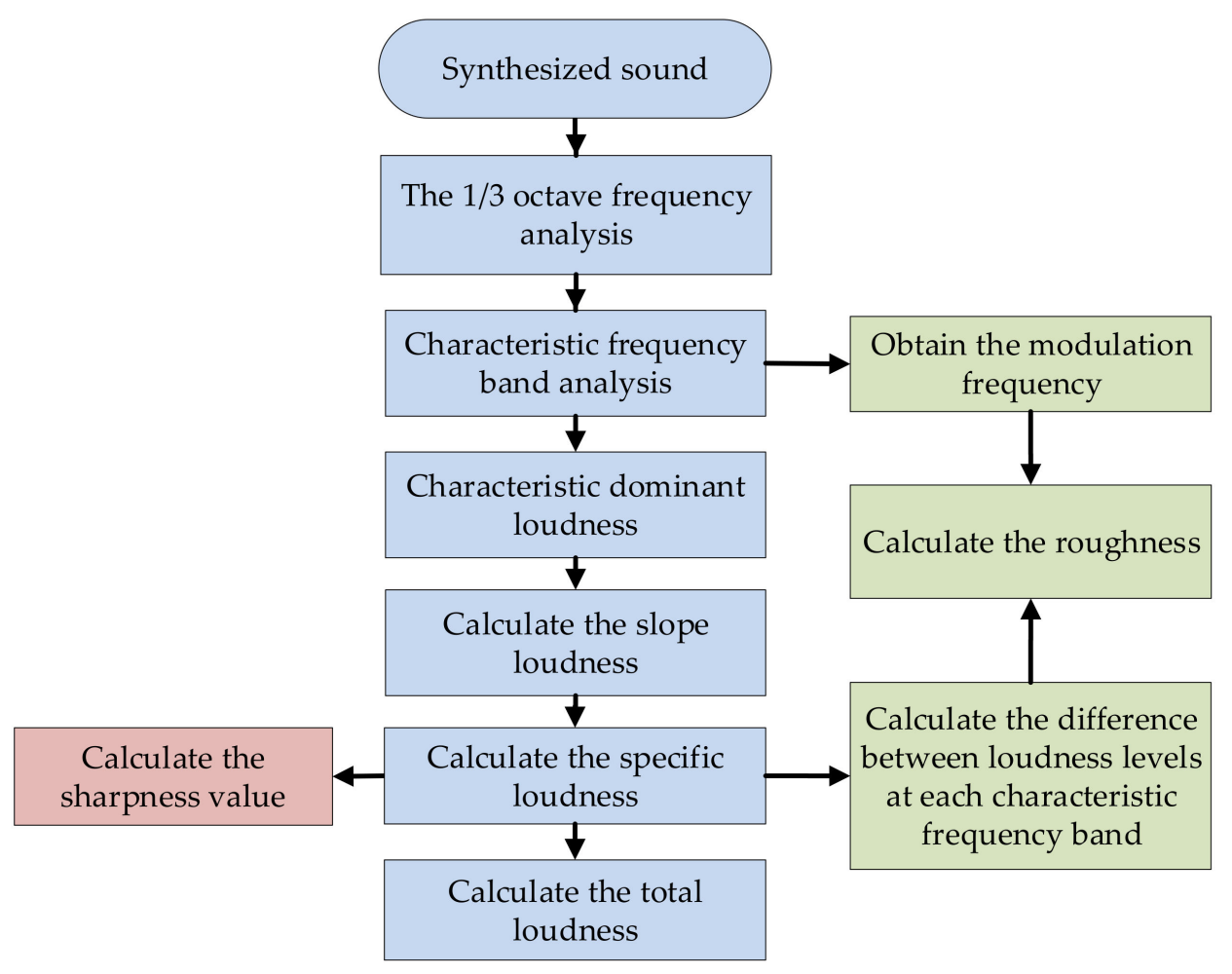

Figure 3. Flowchart for calculating the objective psychoacoustic evaluation parameters of SQ.

Loudness is the degree of subjective perception of the human ear to sound intensity. It is a psychoacoustics parameter that can reflect auditory sensation in terms of which sounds can be ordered on a scale extending from quiet to loud, and it fully takes into account the masking characteristics of the human ear to the sound spectrum. Generally, the larger the loudness value of sound, the more annoying the subjective perception is, and the worse the SQ; however, loudness is not a decisive criterion for evaluating SQ. The unit of loudness is "sone," and the loudness of a $40 \mathrm{~dB}$ pure tone at $1 \mathrm{kHz}$ is defined as 1 sone [23]. Zwicker's loudness model introduced the critical band rate and specific loudness. The total loudness, $\mathrm{N}$, can be obtained by integrating the specific loudness in the Bark scale, as shown in Equation (2):

$$
N=\int_{0}^{24 \text { Bark }} N^{\prime}(z) d z
$$

where $N^{\prime}(z)$ is the specific loudness in units of "Bark". Zwicker proposed using the Bark scale as a spectrum division, similar to the third octave band [22].

Sharpness reflects the frequency characteristics of the sound. Sharpness describes the proportion of high-frequency components in sound, directly reflecting the harshness of the sound. The unit of sharpness is "acum," and the sharpness of 60-dB narrowband noise with a central frequency of $1 \mathrm{kHz}$ and a bandwidth of $160 \mathrm{~Hz}$ is defined as $1 \mathrm{acum}$. The level of noise sharpness is affected by several parameters, such as the central frequency, bandwidth, SPL, and the spectral envelope. Among them, the central frequency and spectrum envelope are identified the most important. In general, the greater the proportion of high-frequency components in the spectral components of sound, the greater the sharpness [24]. Zwicker's model is usually used to calculate sharpness, the mathematical formulation of which is based on Zwicker's loudness model as follows:

$$
S=k \frac{\int_{0}^{24 \text { Bark }} N^{\prime}(z) \cdot z \cdot g(z) d z}{N}
$$


where $S$ is the total sharpness value, $N$ is the total loudness value, $N^{\prime}(z)$ represents the specific loudness in the $z$ Bark, $k$ is the weighting coefficient, and $g(z)$ is the weight coefficient of sound signal in different Bark.

The roughness is a psychoacoustic parameter reflecting the degree, amplitude, and frequency distribution of the modulation, along with other characteristics of sound signals. As a sound-evaluation index, the roughness is applicable to modulation frequencies below $200 \mathrm{~Hz}$, and is especially used at modulation frequencies near $70 \mathrm{~Hz}$. In music psychology, smooth and rough sounds are perceived as harmonious and discordant, respectively. The unit of roughness is asper. A $60 \mathrm{~dB}$ sound with a $1 \mathrm{kHz}$ tone which is $100 \%$ amplitudemodulated at $70 \mathrm{~Hz}$ has a roughness of 1 asper. The roughness model was proposed by Aures and was later optimized by Zwicker and Fastl [25]. The roughness $R$ is calculated as

$$
R=0.3 f_{\text {mod }} \int_{0}^{24 \text { Bark }} \Delta L_{E}(z) d z,
$$

where $R$ is the total roughness value, $f_{\text {mod }}$ is the modulation frequency, and $\Delta L_{E}(z)$ is a function of the critical-band rate defined as

$$
\Delta L_{E}(z)=20 \log _{10}\left(\frac{N_{\max }^{\prime}(z)}{N_{\min }^{\prime}(z)}\right),
$$

where $N_{\min }^{\prime}(z)$ and $N_{\max }^{\prime}(z)$ are the minimum and maximum values of the specific loudness (in $z$-th Bark), respectively [26].

In view of the shortcomings of sound pressure level in the acoustic design and evaluation of PEVs, this paper takes the objective psychoacoustics parameters of SQ as the evaluation index of the interior noise synthesized by TPS, which is an innovation point of this paper. Different noise sources have different contributions to the interior noise. The following section analyzes the contribution of each transfer path, so that the noise sources and transfer path that have a greater impact on the interior SQ of the PEV can be found.

\section{Measurements}

\subsection{Transfer Function Measurements}

The measured transfer function is the most important part of interior sound synthesis. The noise transfer function is an inherent characteristic of the system, describing the attenuation of noise or vibration when unit excitations of the system structure are transmitted along a certain transfer path. In practical measurements, the transfer function is commonly represented by the FRF. Because the accuracy of the FRF determines the accuracy of the interior sound synthesis, the measurement accuracy of the FRF must be improved as far as possible by an appropriate method, which should be selected according to the test situation. Transfer functions are usually measured by direct or reciprocity methods.

(1) In the direct method, the coupling point is excited by a force hammer or exciter, and the excitations are measured first at the coupling point and then at the response point. Force hammer excitation requires no installation, but its direction is difficult to control. The imprecise excitation direction leads to inaccurate measurement of the transfer function. An exciter avoids the drawback of the force hammer. Exciter installation is simple and convenient, and the excitation signal is controllable and repeatable. The exciter can be installed in the direction of the desired excitation, providing strong directional control.

(2) In the reciprocity method, the response at the coupling point is measured by the excitation at the response point. Briefly, reciprocity means that the path in one direction equals the path in the opposite direction. The underlying theory is the reciprocity of linear systems. The reciprocity method is widely used for measuring structure-acoustic and acoustic transfer functions. 


\subsubsection{Airborne Noise Transfer Function Measurements}

The noise transfer function of the electric drive system was measured using the airborne source quantification (ASQ) technique. The ASQ technique quantifies airborne noise sources by determining the contribution level of each noise transfer path. To this end, it considers the transfer path between each noise source and the response at the target point [27]. ASQ can accurately measure the contributions of surface-plate noise sources to the total noise [28]. The noise source excitation characteristics are described in terms of volume acceleration or volume velocity, and the response at the target point is indicated by the sound pressure measured by a microphone [29]. As the electric drive system cannot be treated as a single sound source, its surface was divided into several equal-area meshes. Each grid was considered equivalent to a point source, and its intensity was determined as the acceleration at the center point of the mesh multiplied by the surface area of the mesh. In the general meshing principle, the spacing between the mesh centers is less than half the wavelength of sound waves with the corresponding frequency. However, even when the mesh density does not meet these requirements, ASQ is more accurate than traditional measurements of the airborne noise transfer function (in which volume source measurements are separately collected on each surface of the electric drive system). In this measurement, the electric drive system was divided into 61 squares of side length $8.5 \mathrm{~cm}$, as shown in Figure 4.

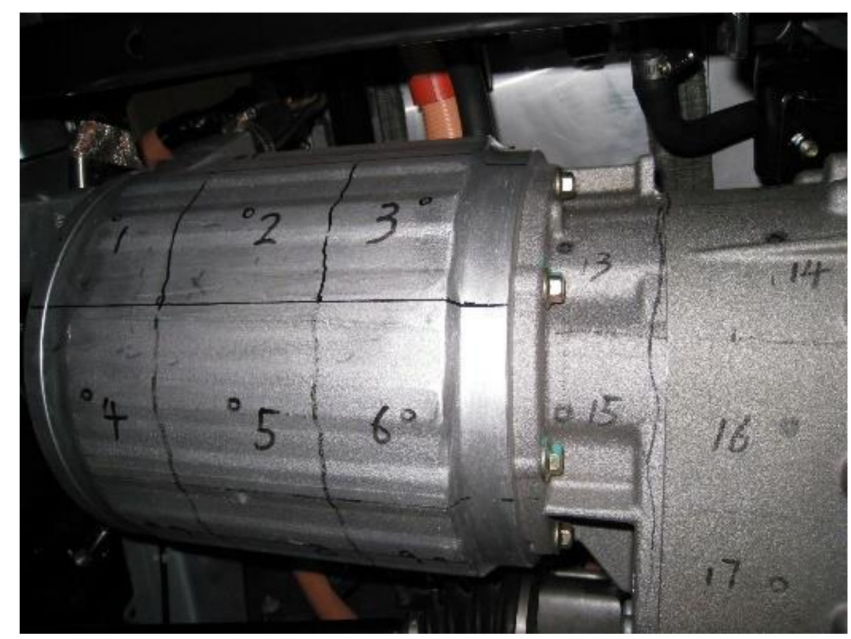

Figure 4. Mesh division of the electric drive system.

The airborne noise transfer path function of the tires was measured using the reciprocity method. Airborne noise transfer functions should be measured in the semi-anechoic chamber of the whole vehicle, and the background noise should be below $25 \mathrm{~dB}$ (A). Airborne noise transfer function measurement equipment is shown in Table 1. In these measurements, we employed a medium- and high-frequency tubular volume sound source with a high signal-to-noise ratio. The nozzle of the volume sound source was positioned at each location of the noise source. The target point in the vehicle (where the microphone was placed) was the position of the driver's right ear. The left and right panels of Figure 5 show the measurement positions of the noise transfer path functions of the left front tire and microphone, respectively. The volume sound source was arranged at each test point to generate white noise, and its sound signal and the signal at the target point in the vehicle were recorded with the microphone. The airborne noise transfer function of each path was then estimated by Equation (6). 
Table 1. Airborne noise transfer function measurement equipment.

\begin{tabular}{ccc}
\hline No. & Equipment & Type \\
\hline 1 & Microphone & B\&K 4189-A-021 \\
\hline 2 & Acoustic calibrator & B\&K 4231 \\
\hline 3 & Data collector & LMS SC316W \\
\hline 4 & Medium-high frequency volume source & LMS SN5114 \\
\hline 5 & Laptop & Dell 5511 \\
\hline
\end{tabular}

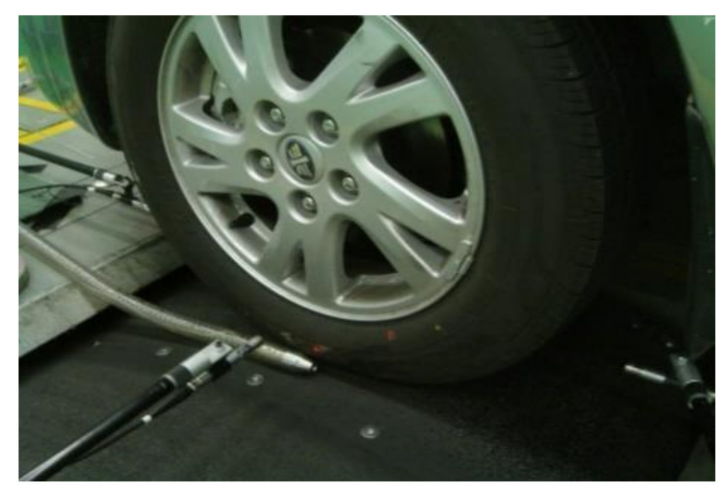

(a)

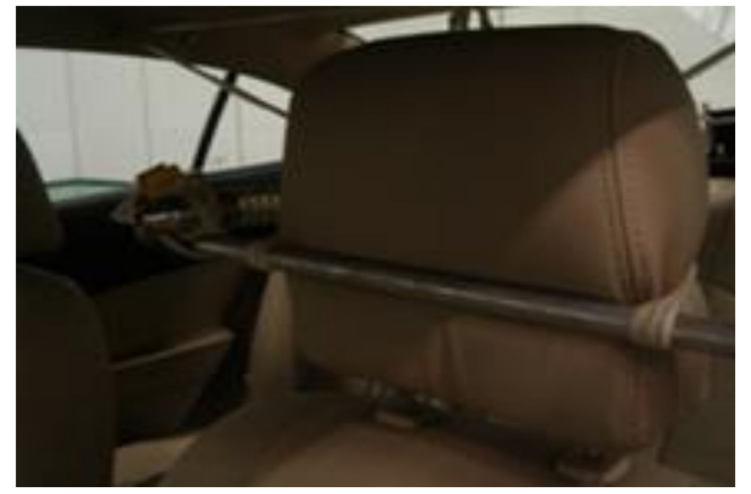

(b)

Figure 5. Measurement position of noise transfer path function of the left front tire: Layouts of (a) the microphone and volume sound source at the left front tire and (b) the microphone placed at the driver's right ear.

Figure 6 displays the spectra of the airborne noise transfer functions from Points 1, 2, and 3 on the motor surface to the target point. Since the amplitude of FRF varies greatly, the $Y$-axis values are displayed on the $\mathrm{dB}$ scale. The $\mathrm{dB}$ scale can clearly express the huge changes of amplitude. At the different surface measurement points, the airborne noise transfer functions showed almost the same trends, with a gradually decreasing sensitivity as the frequency ranged from low to high. The peak frequencies of the noise transfer functions differed among the measurement points, but the differences were ignorable. Figure 7 shows the airborne transfer function spectra of the four tires to the target point.

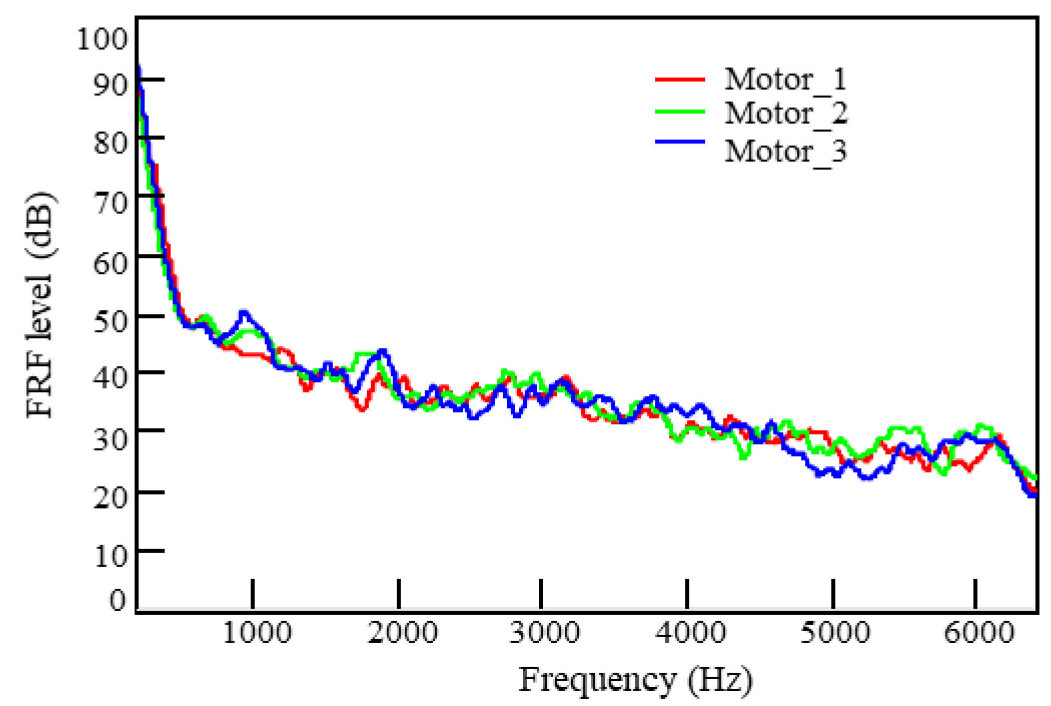

Figure 6. Measured spectra of the noise transfer functions of the motor. 


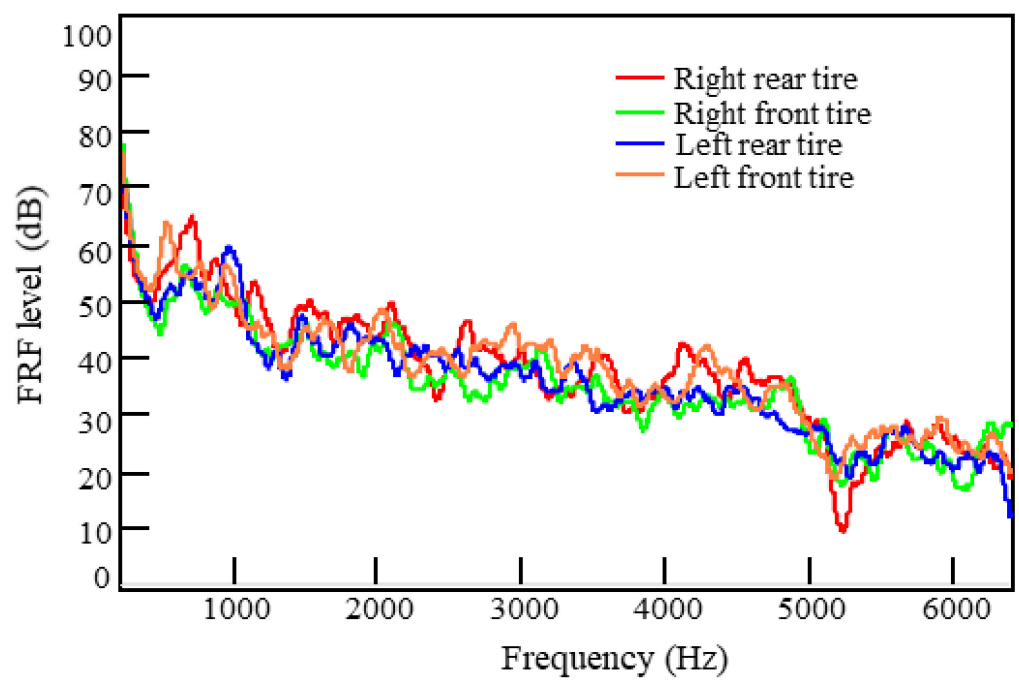

Figure 7. Measured spectra of the noise transfer functions of the tires.

\subsubsection{Structure-Borne Noise Transfer Function Measurements}

Structure-borne noises in PEVs originate from the suspension and mount systems. Structure-borne noise is transmitted as vibrations excited in the $\mathrm{X}, \mathrm{Y}$, and $\mathrm{Z}$ directions from each noise source. The vibrational excitations generated by the electric drive system are attenuated by the mount system, and an exciting force is imparted to the vehicle body. In the driving state of the vehicle, the road excitation is transmitted from the tires to the suspension system, which attenuates the excitation and transmits it to the body, where it is expressed as an exciting force. The exciting force generated by the powertrain system and the road is then transmitted through the body to the wall plate, which produces vibration and radiation noise.

The excitation force of the structure-borne noise source was calculated by the inversematrix method. The inverse-matrix method is appropriate for multi-load identification. For the linear system formed by the noise path in the vehicle, numerous load forces and transfer functions with responses form a matrix relationship, as shown in formula:

$$
\left[\begin{array}{c}
P_{1} \\
\vdots \\
P_{n}
\end{array}\right]=\left[\begin{array}{ccc}
H_{11} & \cdots & H_{1 m} \\
\vdots & \ddots & \vdots \\
H_{n 1} & \cdots & H_{n m}
\end{array}\right]\left[\begin{array}{c}
F_{1} \\
\vdots \\
F_{n}
\end{array}\right],
$$

In the formula, matrix $[\mathrm{P}]$ represents response matrix; matrix $[\mathrm{H}]$ represents path transfer function matrix; matrix [F] represents excitation force matrix [14]. This calculation requires the transfer functions of reference points near the excitation point. The reference points should be as close as possible to the excitation source, and their number should be $2 n$, where $n$ is the number of excitation points. The vibro-acoustic characteristics of the vehicle body reflect the excitation force transferred from the body to the noise inside the vehicle.

Structure-borne noise transfer function measurement equipment is shown in Table 2. For the transfer function measurements, the prototype vehicle was suspended in the free state using a gas spring (see Figure 8). When measuring the transfer function of the mount system, the electric drive system was not completely disassembled, but all mounts of the frame and body were disassembled, and the electric drive system was lifted by hanging (with most of the weight not added to the frame). When measuring the transfer function of the suspension system, the electric drive system and sub-frame were not detached, but all connection points between the front and rear suspensions and the body were disconnected. 
Table 2. Structure-borne noise transfer function measurement equipment.

\begin{tabular}{ccc}
\hline No. & Equipment & Type \\
\hline 1 & Microphone & B\&K 4189-A-021 \\
\hline 2 & Acceleration sensor & KISTLER 8762A \\
\hline 3 & Miniature shaker & LMS A78 \\
\hline 4 & Data collector & LMS SC316W \\
\hline 5 & Power amplifier & LMS SN2249 \\
\hline 6 & Acoustic calibrator & B\&K 4231 \\
\hline 7 & Laptop & Dell 5511
\end{tabular}

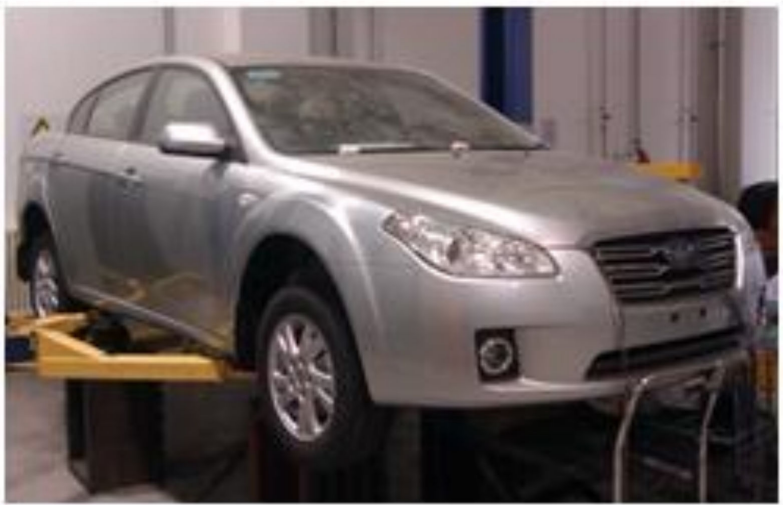

Figure 8. State of the whole vehicle when measuring the structure-borne noise transfer function.

The microphone was arranged at the target point in the vehicle. The position of the target point was unchanged from that of the airborne noise transfer function measurements. The connection points between the suspension and mount system and the body in the X, Y, and $\mathrm{Z}$ directions were excited by a miniature exciter. The sound pressure was recorded at the target points, and the response acceleration was measured at all reference points. For the acceleration measurements, three-direction acceleration sensors were arranged at each reference point near the excitation point. At the large number of measurement and reference points, multiple measurements were collected. To ensure the accuracy of the subsequent load identification, the number of degrees of freedom of the reference point for each measurement was guaranteed to exceed twice the number of degrees of freedom of the excitation point. Figure 9 shows the positions of the exciter and acceleration sensor at the reference point.

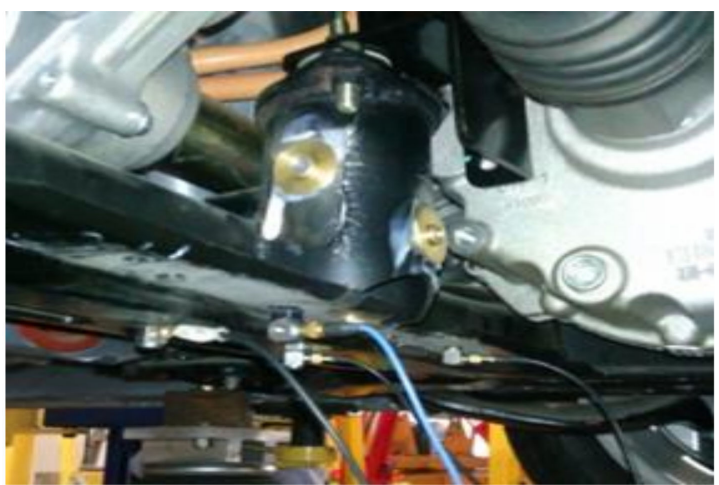

(a)

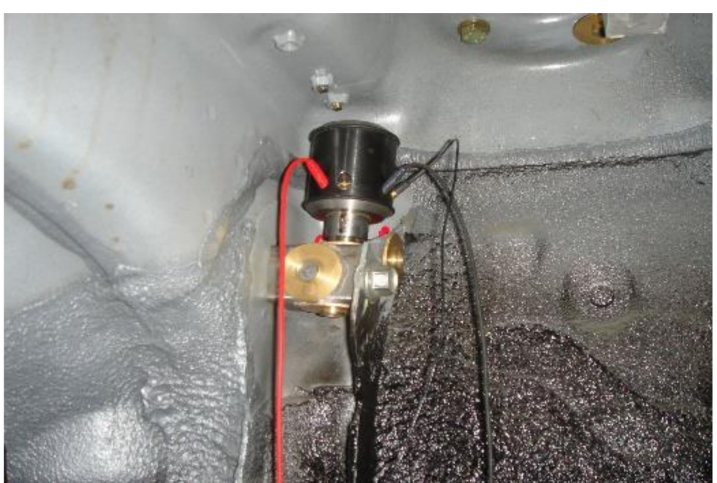

(b)

Figure 9. Positions for measuring the transfer path functions of the mount and suspension: Layouts of (a) the acceleration sensor at the mount and (b) the exciter at the suspension. 
Figure 10 shows the transfer functions of the excitation point of the front mount to the target point of the vehicle in all three directions. As the transfer function became very weak after $500 \mathrm{~Hz}$, only the data between 0 and $500 \mathrm{~Hz}$ were collected for analysis. The transfer function peaked at 10 and $120 \mathrm{~Hz}$. The largest peak was found at $120 \mathrm{~Hz}$. Generally, the most concerning frequencies of interior structure-borne noises caused by the electric drive system were within $300 \mathrm{~Hz}$.

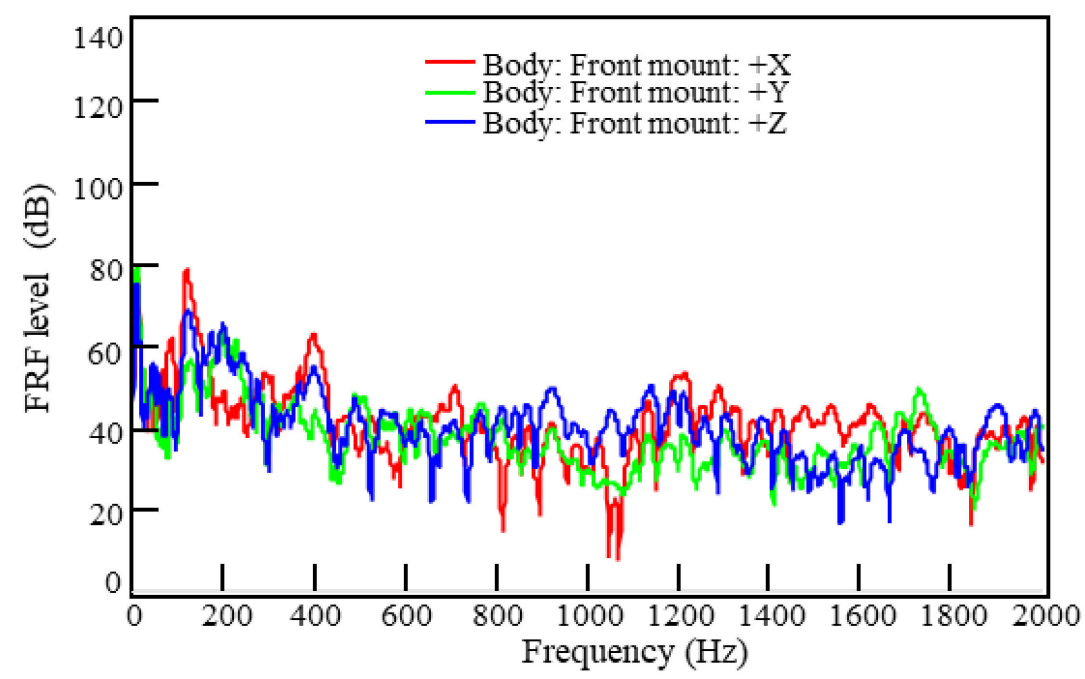

Figure 10. Transfer functions from the three directions of the front mount to the target point in the vehicle.

Figure 11 shows the transfer functions of the front connection of the left rear suspension spring in the three directions to the target point in the vehicle. Since the road test has not been conducted yet, the magnitude of each transfer path excitation source cannot be determined and the sensitivity of the transfer functions can only be analyzed and compared from the test data. Generally, the most concerning frequencies of structure-borne noise in the vehicle caused by the suspension were within $1000 \mathrm{~Hz}$.

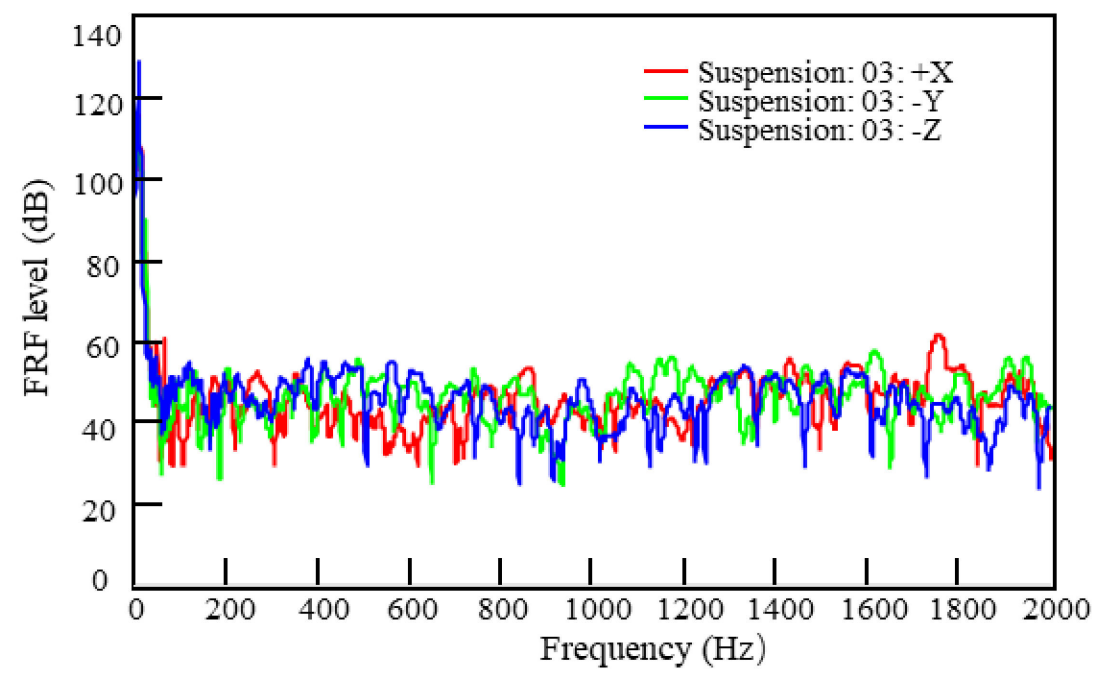

Figure 11. Transfer functions from the three directions of the front connection of the left rear suspension spring to the target point in the vehicle.

\subsection{Noise Source Excitation Measurements}

After measuring the transfer function of the transfer path of each noise source to the target point in the vehicle, we must obtain the working excitation of each noise source 
under actual driving conditions. The excitation data of each noise source were collected in a hub test bench of the vehicle semi-anechoic room. In this environment, the test error is reduced, and the noise influences of wind and the external environment are removed. The vehicle was assumed to be driving at a constant speed under steady-state conditions. During the test, the time domain signal was collected in the 20-60 s period, when the vehicle speed had stabilized. The vehicle and each piece of the test equipment were assumed to operate properly. The data were collected at the target point, noise source excitation point, reference point, and noise-signal phase-reference point in the vehicle. The exciting forces of the mount and suspension systems were obtained using the inverse-matrix method, and the acceleration signals were measured at reference points arranged near each noise source point (where the number of reference points was twice the number of noise source points). The tire excitations were also obtained by the acoustic inverse-matrix method. For this analysis, the sound pressure signals were checked at three reference points near each tire. As the noise transfer functions of the electric drive system were determined by ASQ, they did not require reference points, but a unidirectional acceleration sensor was placed at the center of each noise source point in the electric drive system.

\subsubsection{Airborne Noise Source Excitation Measurements}

For the experimental tests, the surface of the powertrain system noise source was divided into 61 corresponding equal-area grids, each equivalent to a point noise source. The transfer function of this noise source was tested in the previous section. For excitation acquisition, the acceleration signal in each grid of the uniformly steady-state noise source was measured with its one-way acceleration sensor and then multiplied by the grid area to find the source intensity. Each test area of the acceleration signal measurements was consistent with that of the transfer function measurement. The one-way acceleration sensors were arranged in the grid centers, labeled as noise source points 1-3 in Figure 12. The tire-noise excitation was obtained by the acoustic inverse-matrix. In this analysis, three microphones were arranged as reference points around each tire (see Figure 13). Airborne noise source excitation measurement equipment is shown in Table 3.

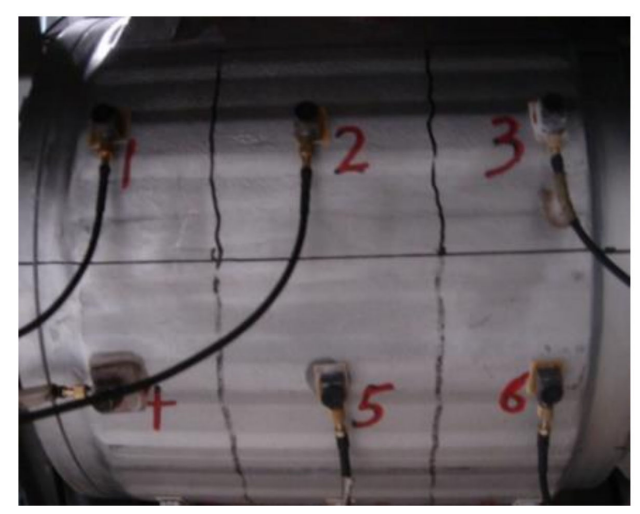

Figure 12. Arrangement of sensors at Points $1-6$ for measuring the motor-acceleration excitations.

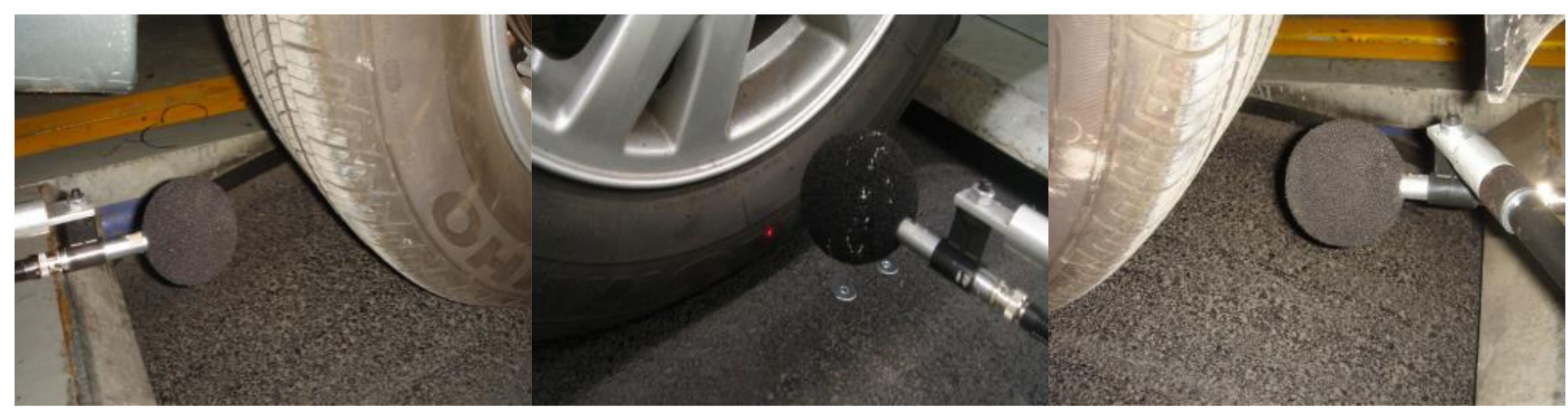

Figure 13. Arrangement of microphones around the front tires of the PEV. 
Table 3. Airborne noise source excitation measurement equipment.

\begin{tabular}{ccc}
\hline No. & Equipment & Type \\
\hline 1 & Microphone & B\&K 4189-A-021 \\
\hline 2 & Acoustic calibrator & B\&K 4231 \\
\hline 3 & Acceleration sensor & KISTLER 8734A \\
\hline 4 & Data collector & LMS SC316W \\
\hline 5 & Laptop & Dell 5511 \\
\hline
\end{tabular}

Figure 14 shows the frequency spectra of the excitation signals at Points 1-3 on the motor surface under the $50 \mathrm{~km} / \mathrm{h}$ working condition. The spectra peaked at 475, 1426, 2375, 2851, 5227, and $5703 \mathrm{~Hz}$. Figure 15 shows the frequency spectra of the three-point excitation signals of the left front tire under the $50 \mathrm{~km} / \mathrm{h}$ working condition. These spectra peaked at $1000-1700 \mathrm{~Hz}$, and the sound pressure slowly decreased as the frequency increased beyond $1700 \mathrm{~Hz}$

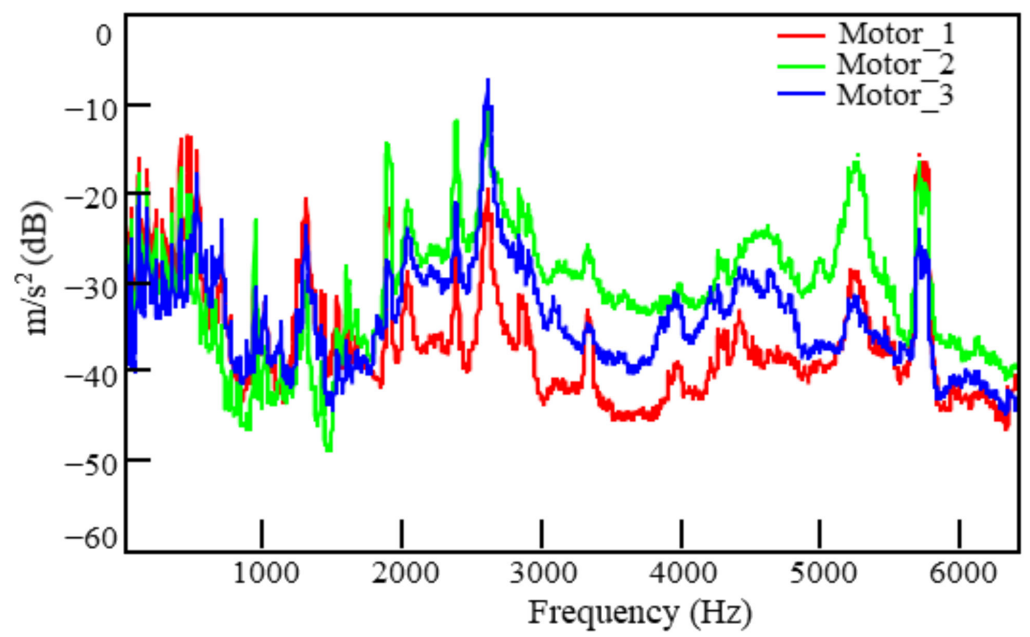

Figure 14. Frequency spectra of excitations at Points 1, 2, and 3 on the motor surface under the $50 \mathrm{~km} / \mathrm{h}$ working condition.

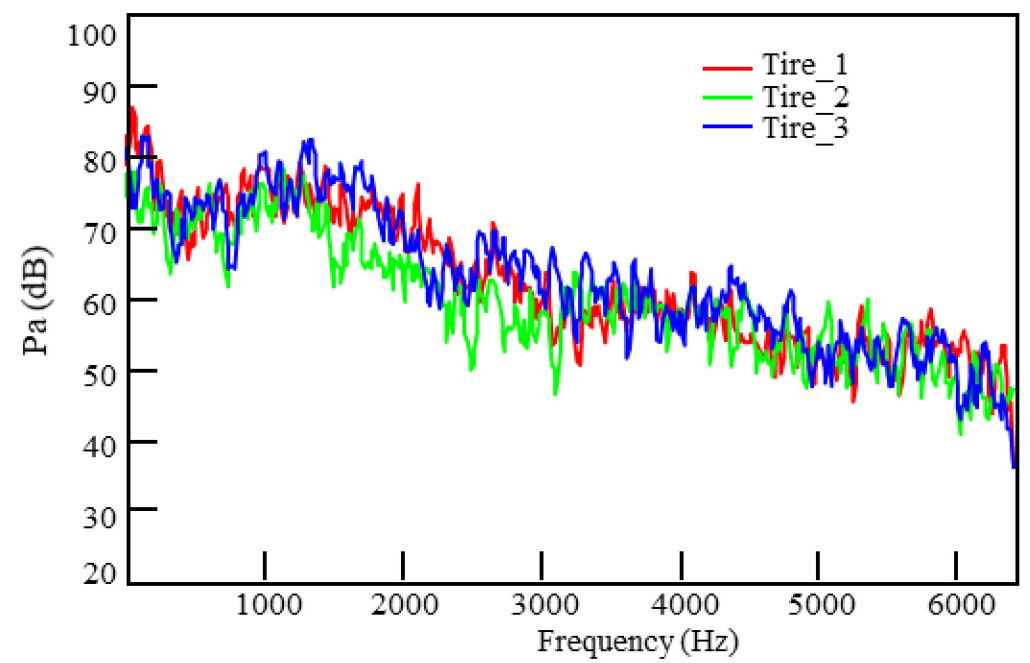

Figure 15. Frequency spectra of excitations of the left front tire under the $50 \mathrm{~km} / \mathrm{h}$ working condition. 


\subsubsection{Structure-Borne Noise Source Excitation Measurements}

Measurements of structure-borne noise source excitation were performed in the same measurement environment under the same standard as the airborne noise source excitation. The noise source excitations of the mount and suspension systems were obtained using the inverse-matrix method, necessitating the arrangement of several vibration acceleration sensors near each structural-sound excitation source. Figures 16 and 17 show the arrangements of the noise source excitation points on the mount and suspension systems, respectively. Structure-borne source excitation measurement equipment is shown in Table 4.

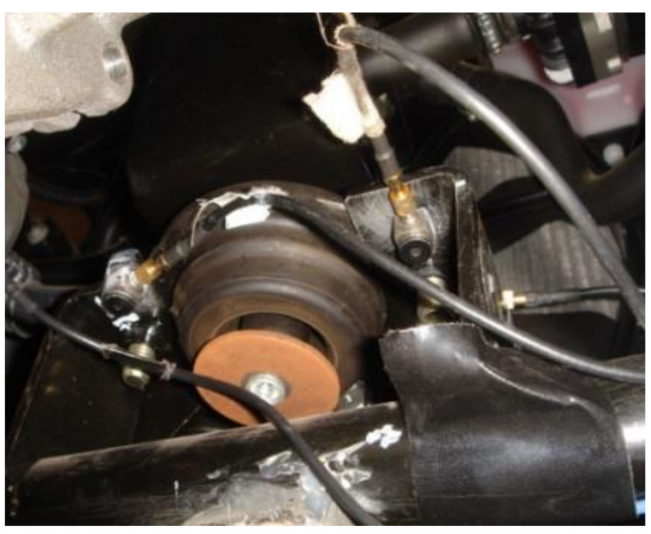

Figure 16. Arrangement of noise source excitation points on the mount front.

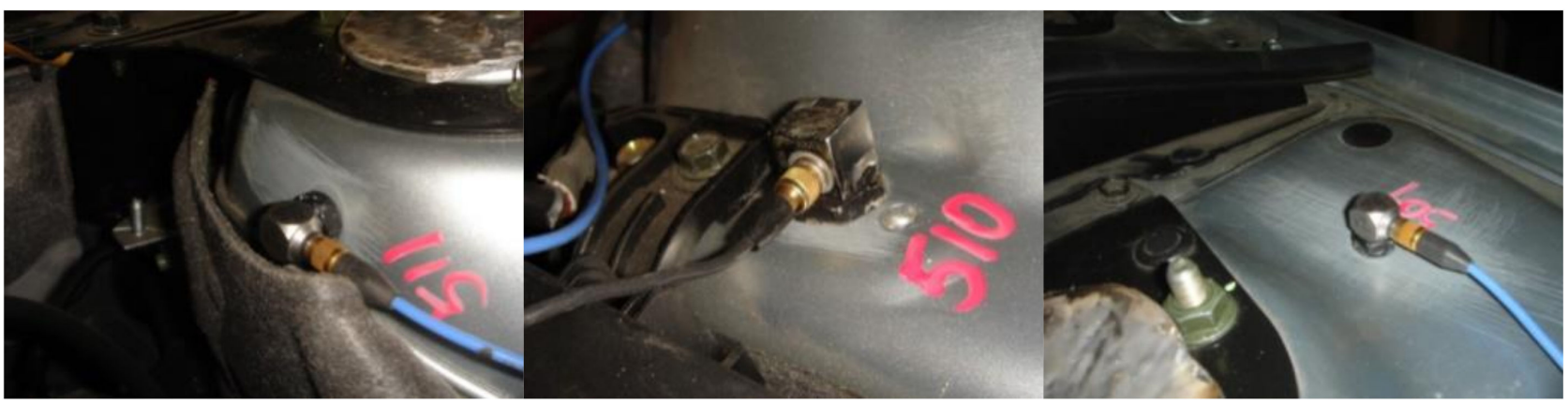

Figure 17. Arrangement of noise source excitation points on the left front suspension.

Table 4. Structure-borne noise source excitation measurement equipment.

\begin{tabular}{ccc}
\hline No. & Equipment & Type \\
\hline 1 & Microphone & B\&K 4189-A-021 \\
\hline 2 & Acceleration sensor & KISTLER 8762A \\
\hline 3 & Acoustic calibrator & B\&K 4231 \\
\hline 4 & Data collector & LMS SC316W \\
\hline 5 & Laptop & Dell 5511
\end{tabular}

Figure 18 shows the excitation spectra in the three directions from Point 2 on the front mount body. The frequencies peaked near 44, 179 and $416 \mathrm{~Hz}$. Figure 19 shows the excitation spectra in the three directions from connection Point 206 on the front of the left rear suspension spring. The frequencies in these spectra peaked near 23, 95, 152, 333 and $478 \mathrm{~Hz}$. 


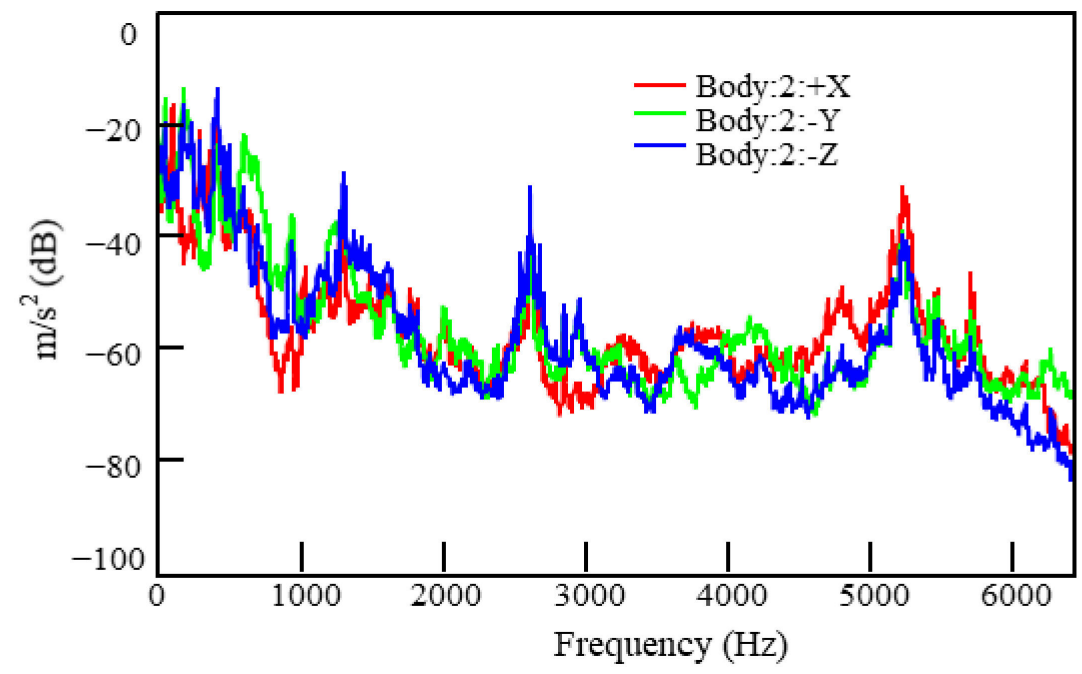

Figure 18. Excitation spectra on the front mount body (in three directions from Point 2).

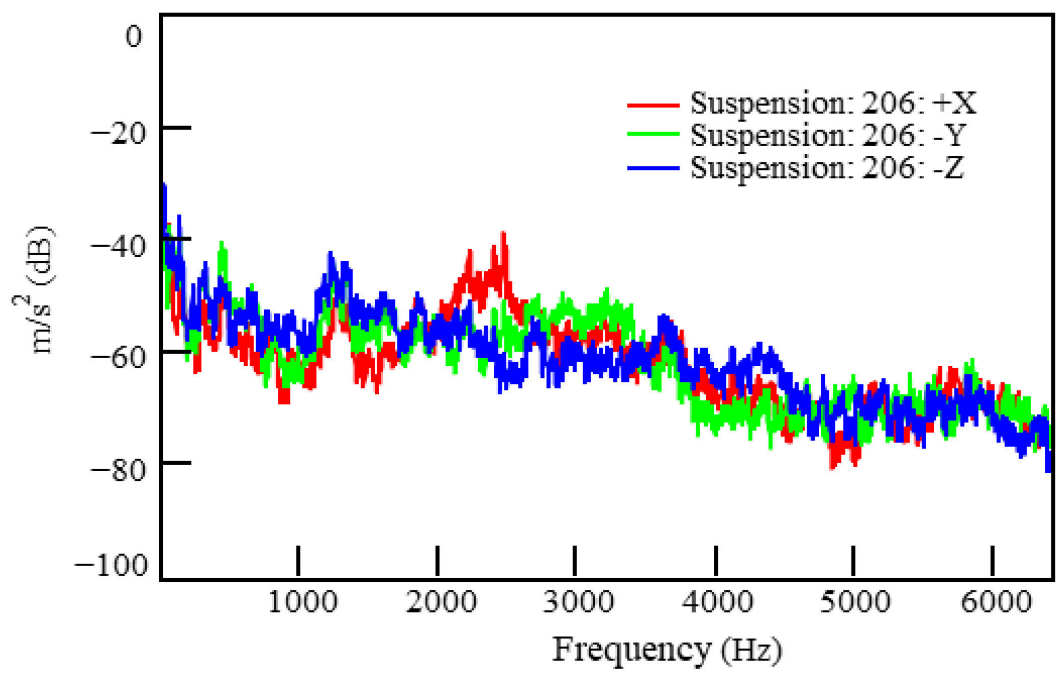

Figure 19. Excitation spectra on the front of the left rear suspension spring (in three directions from Connection Point 206).

\section{Interior Sound Quality Synthesis}

On the basis of the measurement results of the transfer path functions and the working excitations of the different noise sources, the interior noise was simulated under each working condition. For this purpose, a sound-synthetic equivalent model of the PEV was developed. Figure 20 compares the measured and synthesized noise spectra in the PEV under a typical working condition $(50 \mathrm{~km} / \mathrm{h})$. The synthesized and measured noise spectra of the PEV were very similar and followed the same overall change trends. Especially, the peaks at the key frequency points were completely matched. The amplitude differences between the spectral lines of the synthetic and actual in-vehicle noise signals can be explained as follows: (1) Insufficient accuracy of the transfer function measurements, and changes in the stiffness characteristics at the excitation source connection points after removing the electric powertrain and suspension systems; (2) errors in the excitation source data acquisition (despite the use of well-applied methods); and (3) uncertainties and errors in the whole test process introduced by the staff and test equipment. 


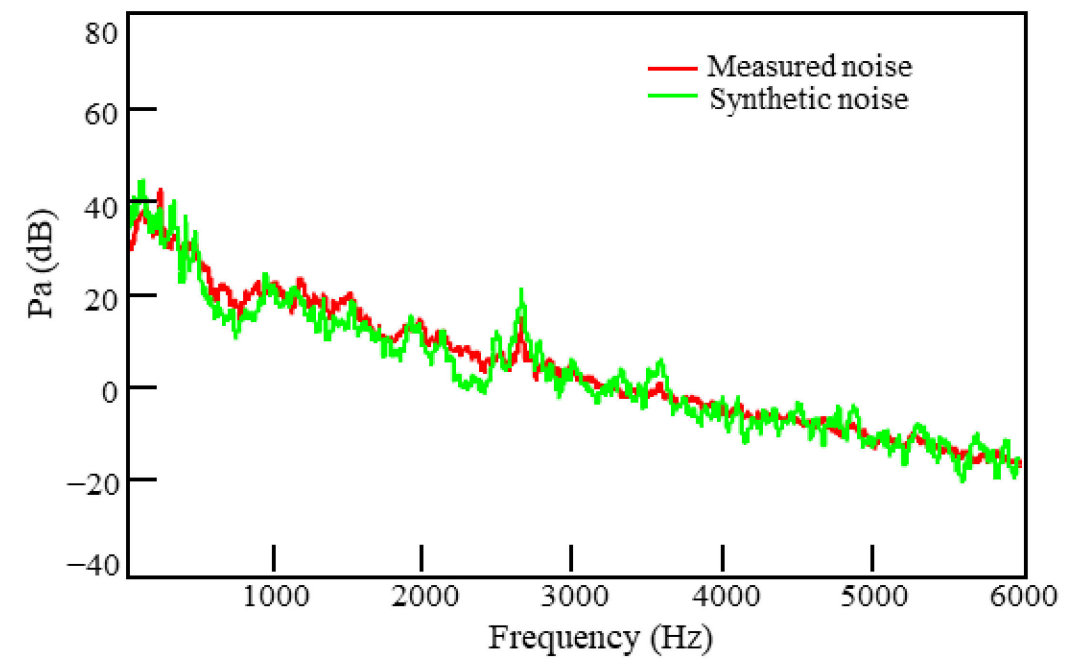

Figure 20. Comparison of synthetic and measured noise spectra in the vehicle operated at a constant speed $(50 \mathrm{~km} / \mathrm{h})$.

Since the transmission path of noise does not change, that is to say, the transfer function does not change with the working conditions, we only need to measure the sound source excitation under different working conditions and put it into the established sound synthesis model to predict the sound in vehicle. As shown in Figure 21, the noise-sound pressure levels in the synthesized vehicle interior at different operating speeds closely matched the measured results. This result indicates the high prediction accuracy of the established synthetic equivalent model. Particularly, the synthesized and actual noise spectra displayed very similar characteristics, guaranteeing the accuracy of the subsequent SQ analysis.

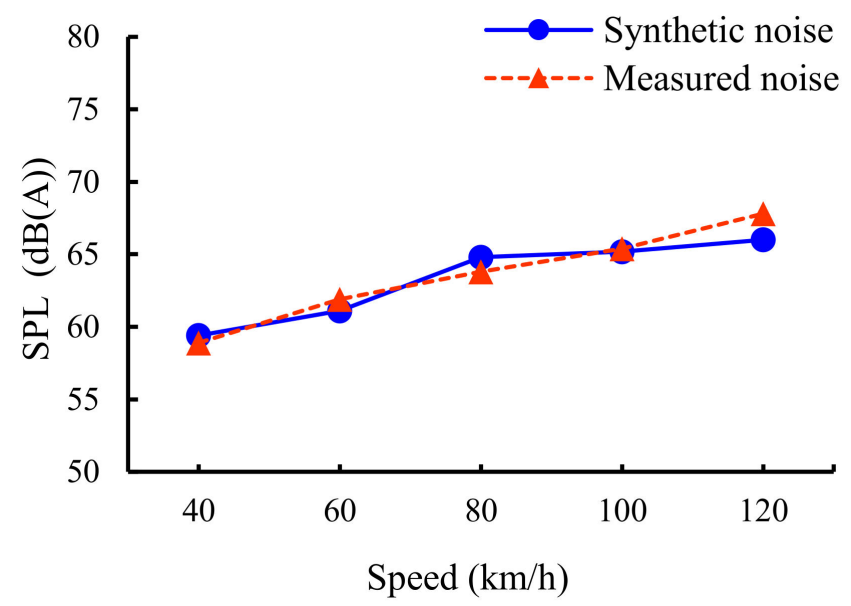

Figure 21. Comparison of synthetic and measured noise-sound pressure levels (SPL) at different operating speeds of the PEV.

The SQ evaluates the subjective feeling invoked by sound. Sound pressure is not the only criterion of SQ. Objective psychoacoustic parameters can systematically describe the different subjective feelings invoked by different sounds. The psychoacoustic parameters comprehensively consider the auditory characteristics of human ears and the physical characteristics of sound. In this study, the objective psychoacoustic parameters of the synthesized interior noise were calculated in a mathematical model implemented in MATLAB R2019b software. Figure 3 provides the calculation procedure, and the results are compared with the measured data in Figures 22-24. 


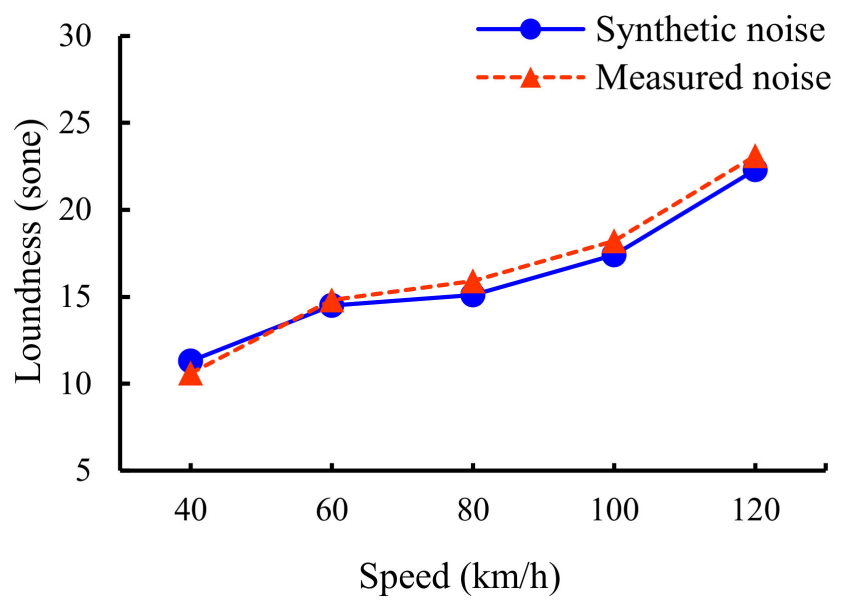

Figure 22. Comparison of synthetic and measured noise loudness at different operating speeds of the PEV.

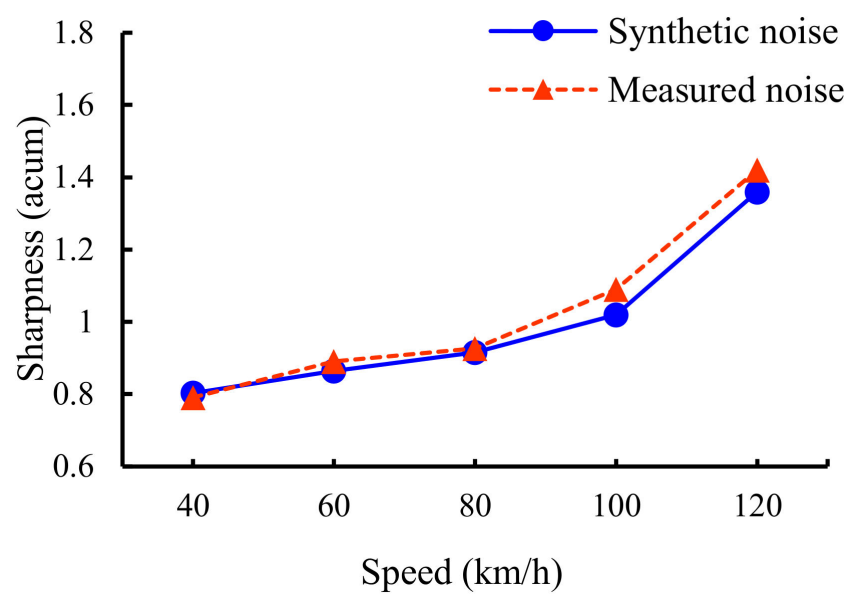

Figure 23. Comparison of synthetic and measured noise sharpness at different operating speeds of the PEV.

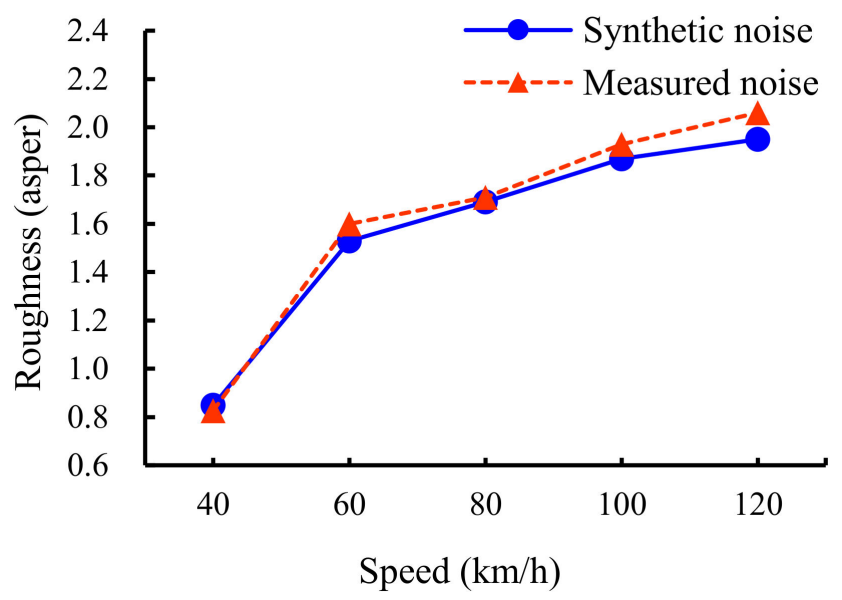

Figure 24. Comparison of synthetic and measured noise roughness at different operating speeds of the PEV.

Under each working condition, the objective SQ parameters of the synthesized and measured interior noises were consistent, and the errors of all parameters were within $7 \%$. This result consolidates the high prediction accuracy of the equivalent synthesis model of the interior noise in a PEV. The model accuracy meets the expected requirements. The 
predicted objective psychoacoustic evaluation parameters almost equaled the measured values (with small errors). Therefore, they can replace the measured interior noise and can objectively express the related acoustic characteristics of PEV noise.

\section{Discussions}

TPA and TPS usually takes the sound pressure level of the interior noise as the evaluation index. TPA and TPS that takes the SQ of interior noise as the target remains in the preliminary exploration stage. According to the established synthesis model of the PEV interior SQ, the contribution of SQ was analyzed and the main noise source and transfer path were found out. In this paper, each path under each working condition is included in the calculation, and the amount of data obtained is large. Therefore, the following is a detailed analysis and introduction of the contribution of various noise sources to the interior SQ under the $50 \mathrm{~km} / \mathrm{h}$ working condition.

The SQ objective parameter value of the transfer paths are shown in Table 5. For sound pressure level and loudness, the contribution from the structure-borne road noise transmitted by suspension system is greater than the other transfer paths. For sharpness and roughness, the contribution from the air-borne noise transmitted by electric drive system is greater than the other transfer paths. Sharpness is an important index to evaluate the interior SQ of PEVs [8]. The sharpness indicates the proportion of the high-frequency sound components, and it can objectively reflect the harshness of sound. The high frequency electromagnetic noise of the electric drive system is very annoying. The radiated noise of the electric drive system has an important effect on the acoustic environment inside PEV.

Table 5. Sound quality contribution to the paths of interior noise of PEV under $50 \mathrm{~km} / \mathrm{h}$.

\begin{tabular}{ccccc}
\hline Contribution & Suspension & Mount & Electric Drive System & Tire \\
\hline Sound pressure level/dB(A) & 57.8 & 50.3 & 52.7 & 49.1 \\
\hline Loudness/sone & 11.4 & 5.1 & 6.5 & 4.5 \\
\hline Sharpness/acum & 0.712 & 0.691 & 0.783 & 0.677 \\
\hline Roughness/asper & 0.439 & 0.629 & 0.513 \\
\hline
\end{tabular}

In this paper, the SQ separation method based on the improved TPA and TPS that takes the SQ of interior noise as the target can identify the main transfer path of interior noise. The contribution of each noise source and transfer path to interior SQ was quantified. TPS that takes the SQ of interior noise as the target can predict the interior SQ transmitted by each transfer path. This paper shows that the SQ separation method is an effective technique to realize the delight sound design for PEVs. In the future, this method can be an effective tool to improve the acoustic environment of PEVs combined with the subjective evaluation method of SQ.

\section{Conclusions}

This study has developed an equivalent SQ model of the interior sound in a PEV. The model synthesis was based on the transfer function path technique, and the model itself considered the airborne noise sources (electric drive system and tire) and structure-borne noise sources (suspension and mount systems). In the established sound equivalent model of the PEV interior, the interior noise was synthesized and simulated under each working condition. The synthesized results well agreed with the measured results and exhibited the same overall trends as the measured spectra. Especially, the peaks of the measured and simulated spectra coincided at the key frequency points. The loudness, sharpness, and roughness values of the synthesized and measured in-vehicle noises differed within $7 \%$ under each working condition, further confirming higher prediction accuracy of the synthetic equivalent model of the interior PEV SQ. The model meets the expected requirements, and the objective psychoacoustic evaluation parameters predicted by the model equaled the measured 
values (within small error margins). TPA and TPS that take the SQ of interior noise as the target can predict the interior SQ transmitted by each transfer path. The model truly reflected the psychoacoustic physical characteristics of the in-vehicle noise. The SQ objective parameter value of each transfer paths was quantified. The structure-borne road noise transmitted by the suspension system and the airborne noise transmitted by the electric drive system have great influence on the interior SQ of PEV. The SQ separation method based on the modified TPA and TPS is an effective technique to realize delight sound design for PEVs. Therefore, it provides a technical basis for the improvement of existing products, new product development, acoustic designs, and SQ evaluations of PEV structures.

Author Contributions: Conceptualization, methodology, data curation, funding acquisition, K.Q.; project administration, writing-review and editing, Z.H.; resources, supervision, validation, visualization, J.L.; formal analysis, investigation, R.L.; writing—original draft preparation, D.S. All authors have read and agreed to the published version of the manuscript.

Funding: This research was funded by the China Postdoctoral Science Foundation, grant number 2019M650657.

Institutional Review Board Statement: Not applicable.

Informed Consent Statement: Not applicable.

Acknowledgments: We would like to thank our mentors and all our colleagues for their help and support.

Conflicts of Interest: The authors declare no conflict of interest.

\section{References}

1. Qian, K.; Hou, Z.; Sun, D.; Wu, P.; Luo, R.; Kuang, K. Objective evaluation of noise in electric vehicles during acceleration based on psychoacoustics. In INTER-NOISE and NOISE-CON Congress and Conference Proceedings; Institute of Noise Control Engineering: Reston, VA, USA, 2020; Volume 261, pp. 2863-2871.

2. Steinbach, L.; Altinsoy, M.E. Prediction of annoyance evaluations of electric vehicle noise by using artificial neural networks. Appl. Acoust. 2019, 145, 149-158. [CrossRef]

3. Deng, W.; Zuo, S. Electromagnetic Vibration and Noise of the Permanent-Magnet Synchronous Motors for Electric Vehicles: An Overview. IEEE Trans. Transp. Electrif. 2018, 5, 59-70. [CrossRef]

4. Swart, D.; Bekker, A.; Bienert, J. The subjective dimensions of sound quality of standard production electric vehicles. Appl. Acoust. 2018, 129, 354-364. [CrossRef]

5. Qian, K.; Hou, Z.; Sun, D. Sound Quality Estimation of Electric Vehicles Based on GA-BP Artificial Neural Networks. Appl. Sci. 2020, 10, 5567. [CrossRef]

6. Huang, H.B.; Wu, J.H.; Huang, X.R.; Yang, M.L.; Ding, W.P. The development of a deep neural network and its application to evaluating the interior sound quality of pure electric vehicles. Mech. Syst. Signal Process. 2019, 120, 98-116. [CrossRef]

7. Steffens, J.; Kueppers, T.; Skoda, S. Psychological factors influencing the evaluation of electric vehicle interior noise. J. Acoust. Soc. Am. 2011, 130, 2546. [CrossRef]

8. Qian, K.; Hou, Z. Intelligent evaluation of the interior sound quality of electric vehicles. Appl. Acoust. 2021, 173, 107684. [CrossRef]

9. Kim, S.J.; Lee, S.K. Prediction of interior noise by excitation force of the powertrain based on hybrid transfer path analysis. Int. J. Automot. Technol. 2008, 9, 577-583. [CrossRef]

10. Kim, S.-J.; Yang, H.-I.; Lee, S.-K. Prediction of Interior Noise Based on Hybrid TPA. SAE Int. J. Passeng. Cars-Mech. Syst. 2009, 2, 1440-1448. [CrossRef]

11. Reising, M.; Küçükay, F.; Eulert, S.; Decker, H.; Luehrs, G.-F. Hybrid acoustic synthesis-Assessment of rear final drives in an early stage of development, on the basis of transfer path analyses and test bench measurements. Appl. Acoust. 2014, 80, 45-56. [CrossRef]

12. Vaitkus, D.; Tcherniak, D.; Brunskog, J. Application of vibro-acoustic operational transfer path analysis. Appl. Acoust. 2019, 154, 201-212. [CrossRef]

13. Ye, S.; Hou, L.; Zhang, P.; Bu, X.; Xiang, J.; Tang, H.; Lin, J. Transfer path analysis and its application in low-frequency vibration reduction of steering wheel of a passenger vehicle. Appl. Acoust. 2020, 157, 107021. [CrossRef]

14. Shang, Z.; Hu, F.; Zeng, F.; Wei, L.; Xu, Q.; Wang, J. Research of transfer path analysis based on contribution factor of sound quality. Appl. Acoust. 2021, 173, 107693. [CrossRef]

15. Comesana, D.F.; Korbasiewicz, M. Evaluation of electric vehicle interior noise focused on sound source identification and transfer path analysis. In Proceedings of the Aachen Acoustics Colloquium, Aachen, Germany, 23 November 2015.

16. Cao, Y.; Wang, D.; Zhao, T.; Liu, X.; Li, C.; Hou, H. Electric Vehicle Interior Noise Contribution Analysis. SAE Tech. Pap. Ser. 2016, 2016-01-1296. [CrossRef] 
17. Diez-Ibarbia, A.; Battarra, M.; Palenzuela, J.; Cervantes, G.; Walsh, S.; De-La-Cruz, M.; Theodossiades, S.; Gagliardini, L. Comparison between transfer path analysis methods on an electric vehicle. Appl. Acoust. 2017, 118, 83-101. [CrossRef]

18. Albers, A.; Fischer, J.; Landes, D.; Behrendt, M. Method for Measuring and Analyzing the Transfer Path of Acoustic Phenomena into the Driver Cabin of a Battery Electric Vehicle. SAE Int. J. Engines 2014, 7, 1585-1592. [CrossRef]

19. Liang, J.; Qian, K.; Wang, J.; Gao, Y.; Sun, Q. Interior noise and vibration prediction of permanent magnet synchronous motor. J. Vibroeng. 2018, 20, 2225-2236. [CrossRef]

20. Lu, M.-H.; Jen, M.U.; de Klerk, D. Noise Source Separation in Electric Vehicles Using Operational Transfer Path Analysis. In INTER-NOISE and NOISE-CON Congress and Conference Proceedings; Institute of Noise Control Engineering: Reston, VA, USA, 2018; Volume 258, pp. 1687-1697.

21. Shiozaki, H.; Iwanaga, Y.; Ito, H.; Takahashi, Y. Interior Noise evaluation of Electric Vehicle: Noise source contribution analysis. In Proceedings of the 1st International Electric Vehicle Technology Conference, Troy, MI, USA, 17 May 2011.

22. Qian, K.; Hou, Z.; Sun, Q.; Gao, Y.; Liu, R.; Sun, D. Sound quality evaluation in the VIP lounge of an EMU train based on psychoacoustic parameters. In INTER-NOISE and NOISE-CON Congress and Conference Proceedings; Institute of Noise Control Engineering: Reston, VA, USA, 2020; Volume 261, pp. 2935-2945.

23. Fastl, H.; Zwicker, E. Loudness; Springer: Berlin/Heidelberg, Germany, 2007; pp. 203-238. [CrossRef]

24. Fastl, H.; Zwicker, E. Sharpness and Sensory Pleasantness. In Psychoacoustics: Facts and Models; Springer: Berlin/Heidelberg, Germany, 2007; pp. 239-246. [CrossRef]

25. Fastl, H.; Zwicker, E. Roughness. In Psychoacoustics: Facts and Models; Springer: Berlin/Heidelberg, Germany, 2007; pp. 257-264. [CrossRef]

26. Qian, K.; Hou, Z.; Sun, Q.; Gao, Y.; Sun, D.; Liu, R. Evaluation and optimization of sound quality in high-speed trains. Appl. Acoust. 2021, 174, 107830. [CrossRef]

27. Kim, B.H.; Shin, T.J.; Lee, S.K. Sound Source Identification Based on Acoustic Source Quantification by Measuring the Particle Velocity Directly. In Proceedings the FISITA 2012 World Automotive Congress, Berlin, Germany, 27-30 November 2013; pp. $279-289$.

28. Byun, J.-H.; Kim, Y.-J.; Kang, Y.J.; Kang, K.-T.; Kwon, O.J.; Hong, J.-C. The Mathematical Model on Crosstalk Effect of Airborne Noise Sources and Verification based on Comparison between Transfer Path Analysis Methods. Trans. Korean Soc. Noise Vib. Eng. 2008, 18, 943-951. [CrossRef]

29. Kim, S.J.; Lee, S.K. Prediction of structure-borne noise caused by the powertrain on the basis of the hybrid transfer path. Proc. Inst. Mech. Eng. Part D J. Automob. Eng. 2009, 223, 485-502. [CrossRef] 